\title{
Are homoeopathic patients conspicuously neurotic?
}

\author{
Timothy Amor, Senior Specialist in Psychiatry, Princess Alexandra Hospital, Royal Air \\ Force Wroughton, Swindon, Wiltshire and JoHN Tod, Senior Specialist in Psychiatry, \\ Royal Air Force Hospital, Wegberg, West Germany, BFPO 40
}

There appears to be a growing public interest in "holistic" and alternative medicine which can be seen as a reaction to the scientific-medical role (Mechanic, 1978) of a conventional medicine which often fails when confronted by emotional or psychosomatic problems, and to fears, by the public, about the side-effects of therapeutic drugs.

Homoeopathy is a well established alternative medicine which is integrated into the NHS, making it accessible to study. The mechanism of action of homoeopathic preparations is not understood, but there is evidence of an active effect (e.g. Reilly et al, 1986) over placebo and, in the past, homoeopathy has had several triumphs over conventional medicine, albeit that the conventional medicine of the time was somewhat barbaric.

At an individual level, the request for homoeopathic treatment can be seen as a special form of helpseeking behaviour (Mechanic, 1978), by patients unfulfilled by conventional medicine. Jenkins et al (1981) found that most patients attending the Royal London Homoeopathic Hospital initiated their own referral because they were dissatisfied with conventional treatment.

Psychosomatic or functional illness is common in general medical and surgical settings (Ford et al, 1987; Macaulay et al, 1987). We ask whether it is predominantly this kind of illness which presents to the homoeopath. If this were so, we would expect to find an excess of neurotic disorder in these patients.

\section{The study}

Fifty consecutive new out-patients at the Royal London Homoeopathic Hospital were asked to complete a questionnaire about their treatment, means of referral and family and personal history of psychiatric disorder. They were also asked to complete the General Health Questionnaire, 30-question edition (GHQ 30) (Goldberg, 1978), which was chosen for its brevity and partial exclusion of questions with a physical illness orientation. Data were subjected to $t$-test and Chi-squared analysis.

Only 34 patients $(68 \%)$ responded. Of these, 27 $(79 \%)$ were female, mean age 51.7 years (range 21-72 years), $13(38 \%)$ had previously consulted a homoeopath, $16(47 \%)$ were referred by their GPs, 8 (24\%) were currently also receiving conventional medicines and $23(68 \%)$ believed that conventional medicines had made no difference to their conditions or had actually damaged them. Seven $(21 \%)$ had never had conventional treatment for their complaints.

Average GHQ score was 6.4 (range 0-26). Patients referred by their GPs had significantly $(P<0.01)$ higher scores (mean 7.7) than patients who were self or "other" referred (mean 5.1). Sixteen patients $(47 \%)$ scored 5 or more on the GHQ 30 , and ten patients $(29 \%)$ scored 9 or more. There was a significant relationship $(P<0.05)$ between high scorers and young age. There was a trend towards high scorers having had a personal psychiatric history; however, there was no relationship between GHQ score and sex, previous homoeopathic treatment, dissatisfaction with conventional medicine, current treatment and family history of psychiatric disorder.

\section{Comment}

Unfortunately, we know nothing about the nonresponders and cannot say whether or not they differed in some way from the patients described. The age distribution of our sample differed significantly from that described by Jenkins et al (1981), although the preponderance of females appears to be typical.

We did not find evidence of an excess of minor psychiatric morbidity in homoeopathic patients who responded to our questionnaires. The GHQ scores compared favourably with those found in general practice (Finlay-Jones \& Murphy, 1979). FinlayJones \& Murphy (1979) recommended a higher cutoff for the GHQ 30, suggesting 8/9 as the threshold for neurotic disorders. The $29 \%$ of patients who scored 9 or more in our study is very similar to the prevalence of morbidity described in general practice (Goldberg \& Blackwell, 1970). The association between GP referral and high GHQ score was unexpected, perhaps indicating that these patients form a special subgroup with increased neurotic morbidity, conforming in part with our original hypothesis that some homoeopathic patients have psychosomatic disorders with special treatment needs. However, this group of patients was not disenchanted with 
conventional medicine; perhaps the reciprocal of this could be true: that their GPs could have been disenchanted with them. Young age had a significant relationship with high GHQ score, but this is consistent with the tendency for the score to reduce beyond age 30 (Goldberg, 1978). It is quite tenable that we missed a number of somatizers because of their denial of emotional disturbance.

This is a potentially fruitful, and largely unstudied, field. We recommend that further research be conducted to ascertain the nature and needs of those who seek alternative medicine since this may shed light on conventional medicine's own failings and need for change.

This paper is the opinion of the authors and does not represent the views of the Ministry of Defence.

\section{Acknowledgement}

The authors would like to thank Dr A. Campbell, Consultant Physician, the Royal London Homoeopathic Hospital for permitting this study to be conducted.

\section{Crown Copyright Reserved}

\section{References}

FINLAY-JONES, R. \& MURPHY, E. (1979) Severity of psychiatric disorder and the 30-item General Health Questionnaire. British Journal of Psychiatry, 134, 609-616.

Ford, M. J., MILLER, P. MCC., EAsTwOOd, J. \& EAsTwOOd, M. A. (1987) Life events, psychiatric illness and the irritable bowel syndrome. Gut, 28, 160-165.

Goldberg, D. P. \& BlACKWELl, B. (1970) Psychiatric illness in general practice. A detailed study using a new method of case identification. British Medical Journal, 2 , 439-443.

(1978) Manual of the General Health Questionnaire. NFER Publishing.

Jenkins, S., Jenkins, M. D. \& Campbell, A. (1981) A survey of 500 consecutive new patients attending medical outpatients at the Royal London Homoeopathic Hospital. The British Homoeopathic Journal, 70, 23-26.

Macaulay, A. J., Stern, R. S., Holmes, D. M. \& Stanton, S. L. (1987) Micturition and the mind: Psychological factors in the aetiology and treatment of urinary symptoms in women. British Medical Journal, 1, 540-543.

Mechanic, D. (1978) Medical Sociology, Second edition. New York: The Free Press; Macmillan Publishing. London: Collier Macmillan.

Reilly, D. T., TAYLOR, M. A., McSharry, C. \& AIrchison, T. (1986) Is homeopathy a placebo response? Controlled trial of homoeopathic potency, with pollen in hayfever as model. Lancet, 2, 881-886 